Article

\title{
Legionella spp. Colonization in Water Systems of Hotels Linked with Travel-Associated Legionnaires' Disease
}

\author{
Antonios Papadakis ${ }^{1,2,+} \mathbb{D}$, Maria Keramarou ${ }^{3,+}$, Dimosthenis Chochlakis ${ }^{1,3} \mathbb{D}$, Vassilios Sandalakis ${ }^{1} \mathbb{D}$, \\ Varvara A. Mouchtouri ${ }^{4}$ and Anna Psaroulaki 1,3,*
}

1 Department of Clinical Microbiology and Microbial Pathogenesis, School of Medicine, University of Crete, Voutes-Staurakia, 71110 Heraklion, Greece; ant.papadakis@yahoo.gr (A.P.); surreydimos@hotmail.com (D.C.); v.sandalakis@uoc.gr (V.S.)

2 Laboratory of Hygiene and Environmental Protection, Faculty of Medicine, Democritus University of Thrace, 68100 Alexandroupoli, Greece

3 Regional Laboratory of Public Health, School of Medicine, 71110 Heraklion, Greece; keramarou@gmail.com

4 Laboratory of Hygiene and Epidemiology, Faculty of Medicine, University of Thessaly, 41222 Larissa, Greece; mouchtourib@uth.gr

* Correspondence: psaroulaki@uoc.gr; Tel.: +30-2810-039-4743

+ These authors contributed equally to this work.

check for updates

Citation: Papadakis, A.; Keramarou, M.; Chochlakis, D.; Sandalakis, V.; Mouchtouri, V.A.; Psaroulaki, A. Legionella spp. Colonization in Water Systems of Hotels Linked with Travel-Associated Legionnaires' Disease. Water 2021, 13, 2243. https://doi.org/10.3390/w13162243

Academic Editor:

Helvi Heinonen-Tanski

Received: 26 June 2021

Accepted: 14 August 2021

Published: 17 August 2021

Publisher's Note: MDPI stays neutral with regard to jurisdictional claims in published maps and institutional affiliations.

Copyright: (c) 2021 by the authors. Licensee MDPI, Basel, Switzerland. This article is an open access article distributed under the terms and conditions of the Creative Commons Attribution (CC BY) license (https:/ / creativecommons.org/licenses/by/ $4.0 /)$.
Abstract: Hotel water systems colonized with Legionella spp. have been the source of travel-associated Legionnaires' disease, and cases, clusters and outbreaks continue to be reported worldwide each year. A total of 132 hotels linked with travel-associated Legionnaires' disease, as reported through the European Legionnaires' Disease Surveillance Network, were inspected and tested for Legionella spp. during 2000-2019 by the public health authorities of the island of Crete (Greece). A total of 3311 samples were collected: 1885 (56.93\%) from cold water supply systems, 1387 (41.89\%) from hot water supply systems, $37(1.12 \%)$ were swab samples and two $(0.06 \%)$ were soil. Of those, $685(20.69 \%)$, were collected from $83(62.89 \%)$ hotels, testing positive ( $\geq 50$ CFU/L) for Legionella pneumophila) serogroups 1-10, 12-14 and non-pneumophila species (L. anisa, L. erythra, L. tusconensis, L. taurinensis, L. birminghamensis, L. rubrilucens, L. londiniesis, L. oakridgensis, L. santicrusis, L. brunensis, L. maceacherii). The most frequently isolated L. pneumophila serogroups were $1(27.92 \%)$ and $3(17.08 \%)$. Significantly higher isolation rates were obtained from hot water supply systems $(25.96 \%)$ versus cold water systems $(16.98 \%)$ and swab samples $(13.51 \%)$. A Relative Risk (R.R.) > $1(p<0.0001)$ was calculated for hot water temperature $<55{ }^{\circ} \mathrm{C}$ (R.R.: 4.43), chlorine concentrations $<0.2 \mathrm{mg} / \mathrm{L}$ (R.R.: 2.69), star ratings $<4$ (R.R.: 1.73) and absence of Water Safety Plan implementation (R.R.: 1.57).

Keywords: Legionella; water systems; risk; water safety plan; hotel

\section{Introduction}

Hotel water systems can be colonized with Legionella spp. and can serve as a source for travel-associated Legionnaires' disease (TALD) [1]. Travelers infected in the country that they visit are usually diagnosed in their home country after returning from holidays. The European Legionnaires' Disease Surveillance Network (ELDSNet) at the European Center for Disease Prevention and Control (ECDC) conducts surveillance of Legionnaires' disease at the European Union level. Public health authorities in Crete conduct an inspection, including risk assessment and water sampling, each time a case, cluster or outbreak is reported through ELDSNet among tourists who have stayed in a hotel in Crete. Furthermore, the public health authorities, through ELDSNet, provide details about the actions taken in accordance with the operating procedures [1].

A total of 1657 cases of TALD with a date of onset in 2019 were reported to ECDC by 28 countries, including Greece [2]. In Greece, studies conducted in previous years have demonstrated Legionella spp. colonization of hotels' water systems [3-7]. The national legislative framework requires regular monitoring, as well as preventive and control measures 
in accordance with the European and World Health Organization (WHO) guidelines [8,9]. WHO makes suggestions regarding water system construction, design, routine operational monitoring and management incorporated in water safety plans developed by building owners or managers [8]. We report results of risk assessment and testing for Legionella spp. at hotels in Crete where tourists who developed Legionnaires' disease had stayed and had been reported on through ELDSNet, together with an analysis of inspection results and water safety practices implemented in these hotels.

The objectives of the present study were to: (a) determine the level of colonization of Legionella spp. in hotel water supply systems that have been associated with TALD, and (b) identify the risk factors associated with Legionella colonization of hotel water systems that have been associated with TALD.

\section{Materials and Methods}

\subsection{Sample Collection}

From 2000 to 2019, the public health authorities in Crete, Greece inspected a total of 132 hotels that were associated with TALD, as reported through ELDSNet. In accordance with national guidelines and procedures, samples were taken from hotel water systems, including water tanks, hotel room outlets, showers located in swimming pools and spas, garden sprinklers and soil, where applicable.

The sample collection and site selection processes were in accordance with: (a) the European Technical Guidelines for the Prevention, Control and Investigation of Infections Caused by Legionella species and (b) the international standard methods: ISO 5667-2:1982Part 2: guidance on sampling techniques, while since 2006 samples were collected following the ISO 19458:2006 Water quality-Sampling for microbiological analysis methodology [9-11]. The samples were labeled and temporarily stored in a cool box at a temperature of up to $5( \pm 3){ }^{\circ} \mathrm{C}$, protected from direct light, before being delivered to the laboratory immediately after the sampling (no more than $24 \mathrm{~h}$ ).

\subsection{Risk Assessment, Data Collection and Corrective Action}

Inspections were conducted following the European technical guidelines [9]. Water temperature was measured by placing a calibrated thermometer sensor in the middle of the water stream, two minutes after flushing. A portable calibrated microprocessor-based meter was used to measure $\mathrm{pH}$ and free chlorine, and $1 \mathrm{~L}$ sterile containers containing sodium thiosulphate $(20 \mathrm{mg})$ were used for sample collection. Risk assessment and corrective actions were implemented in accordance with the European guidelines for water systems linked with TALD [9]. For each hotel water system, the following information was recorded: chlorine concentration, water temperature, $\mathrm{pH}$, type of water disinfection applied, hotel star rating, seasonal hotel operation, hotel capacity in rooms/beds, water safety plan (WSP) implementation, and type of water supply, type of hot water production system, water system maintenance and cleaning frequency.

\subsection{Plate Culture Method}

Legionella was isolated by culture in accordance with the international standard methods ISO 11731 (1998), and after 2004 with ISO 11731-2 (2004). Water samples were concentrated by filtration and were re-suspended in distilled deionized water. A volume of the suspension $(200 \mu \mathrm{L})$ was spread on BCYE (Buffered Charcoal Yeast Extract), BCYE minus cysteine and GVPC (Glycine Vancomycin Polymyxin Cycloheximide) (Biomérieux, Craponne, France) Petri dishes: (a) directly after filtration; (b) after incubation at $50{ }^{\circ} \mathrm{C}$ for $30 \mathrm{~min}$; (c) after the addition of an acid buffer $(0.2 \mathrm{~mol} / \mathrm{L}$ solution of $\mathrm{HCl}, \mathrm{pH} 2.2$ for at least $15 \mathrm{~min}$ ). The detection limit of the procedure was $50 \mathrm{CFU} / \mathrm{L}$. The inoculated plates were incubated for 10 days at $36 \pm 1{ }^{\circ} \mathrm{C}$ in $2.5 \% \mathrm{CO}_{2}$ with increased humidity. Suspected colonies were randomly chosen for subculture on BCYE minus cysteine, BCYE and GVPC agar. 


\subsection{Typing of Legionella Isolates}

The agglutination test (SLIDEX Legionella-Kit, Biomérieux, Craponne, France) was used to identify the isolated colonies, including to distinguish between L. pneumophila serogroup 1 and serogroups 2-14 and of L. anisa. Individual latex polyclonal reagents were used (Pro-lab, Richmond Hill, ON, Canada) for the exact detection of each L. pneumophila serogroup.

\subsection{Identification-MALDI-TOF Mass Spectrometry}

Since 2010, identification of individual Legionella colonies against their microbial database (v 3.1.2.0) has taken place with the MALDI Biotyper (Microflex LT MALDI-TOF mass spectrometer) (Bruker Daltonics, Leipzig, Germany) equipped with a microSCOUT ion source. Spectra were recorded using the flexControl software with the default parameters for optimization set by the manufacturer (Bruker Daltonics, Leipzig, Germany). For each spectrum, 240 laser shots were collected and analyzed $(6 * 40$ laser shots from 120 different positions of the target spot). All identifications were evaluated according to the manufacturers' scoring scheme.

\subsection{Statistical Analysis}

The IBM SPSS Statistics Version 24 statistical package and the Epi-Info 2000 version 7.2.0.1 (Centers for Disease Control and Prevention, Atlanta, GA, USA) were used for statistical analysis. Categorical risk variables from water distribution systems and hotel characteristics were assessed for association with Legionellae-positive test results. A proportional z-test was calculated to test for significant differences between the sampling site and Legionella pneumophila serogroup 1 versus serogroups $2-15$, serogroup 1 versus Legionella non pneumophila, and serogroups $2-15$ versus Legionella non pneumophila. When the $p$ value was $<0.05$, the results were considered statistically significant, and they were considered highly significant when the $p$ value was $<0.0001$.

\section{Results}

\subsection{Descriptive Data}

Of the 3311 samples collected, 685 (20.69\%), originating from $83(62.89 \%)$ hotels, tested positive ( $\geq 50 \mathrm{CFU} / \mathrm{L}$ ) for Legionella (Legionella pneumophila) serogroups 1-10, 12-14 and non-pneumophila species: L. anisa, L. erythra, L. tusconensis, L. taurinensis, L. birminghamensis, L. rubrilucens, L. londiniesis, L. oakridgensis, L. santicrusis, L. brunensis, L. maceacherii). Table S1 presents the summary laboratory examination results for Legionella spp. by culture per sample type. The most frequently isolated L. pneumophila serogroups were $1(27.92 \%)$ and $3(17.08 \%)$. In $70(55.12 \%)$ hotel cold water distribution systems, 297 (16.66\%) samples tested positive. In 66 (53.23\%) hotel hot water distribution systems, 345 (26.29\%) samples tested positive. In five (35.71\%) hotels, six $(15.38 \%)$ swab samples tested positive. Table 1 presents the results of Legionella spp. colonization of hotel water systems linked with travel-associated Legionnaires' disease according to the sampling site, as well as the results of associations between the different serogroups and L. pneumophila in comparison with non-pneumophila. Table 2 presents the level of Legionella spp. colonization of the hotel water systems. 
Table 1. Legionella spp. colonization of hotel water systems linked with travel-associated Legionnaires' disease (TALD) on the island of Crete, Greece.

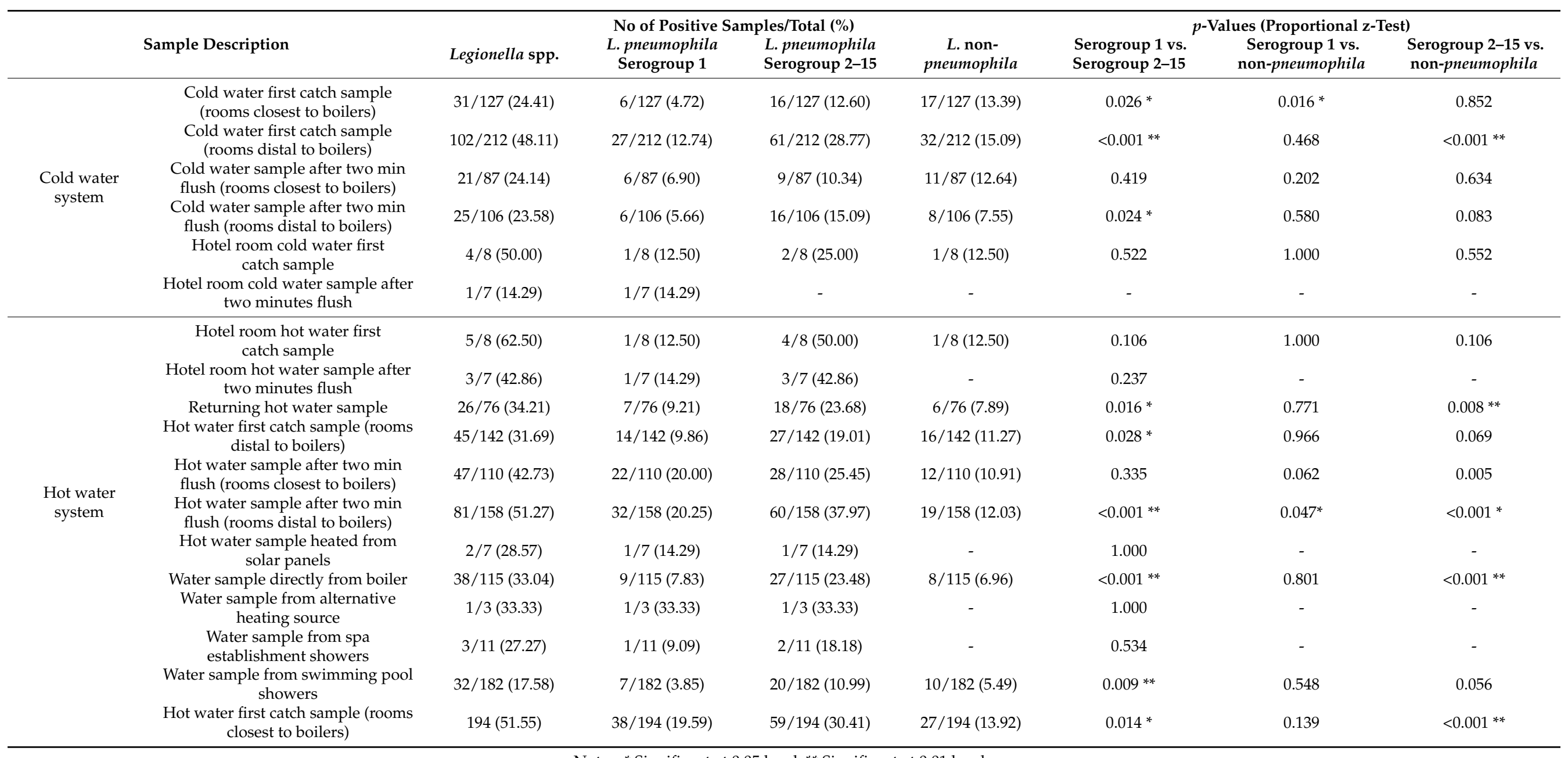


Table 2. Level of Legionella spp. colonization of hotel water systems (CFU/L).

\begin{tabular}{|c|c|c|c|c|}
\hline \multirow{2}{*}{ Sample Type } & \multicolumn{4}{|c|}{ Number of Samples } \\
\hline & Low $(\leq 1.000)$ & Medium $(>1.000 \&<10.000)$ & High $(\geq 10.000)$ & Total \\
\hline Cold water distribution system & $177(57.84)$ & $79(35.11)$ & $64(41.56)$ & 320 \\
\hline Hot water distribution system & $129(42.16)$ & $144(64.00)$ & 87 (56.49) & 360 \\
\hline $\begin{array}{l}\text { Sediment from room shower water } \\
\text { sample and from filtering systems }\end{array}$ & $0(0.00)$ & $2(0.89)$ & $3(1.95)$ & 5 \\
\hline Soil & $0(0.00)$ & $0(0.00)$ & $0(0.00)$ & 0 \\
\hline Total $(n)$ & $306(44.67)$ & $225(32.80)$ & $154(22.48)$ & 685 \\
\hline
\end{tabular}

\subsection{Isolation and Identification of Legionella Species}

Legionella was isolated from both hot and cold water systems (Tables 2 and 3). The following serogroups of Legionella pneumophila were detected: 1, 2, 3, 6, 7, 8, 13, 14 and 2-15. Moreover, L. anisa, L. erythra, L. taurinensis, L. birminghamensis and L. rubrilucens were detected. Table S2 presents the concentrations of Legionella non-pneumophila spp. in water samples (CFU/L).

Table 3. Legionella spp. concentration (CFU/L) per serogroup and level of colonization.

\begin{tabular}{|c|c|c|c|c|}
\hline Legionella Species and Serogroup (sg) & & Legionella spp. C & ration $(C F L$ & \\
\hline Species & $\leq 10^{3}(\%)$ & $>10^{3}$ and $<10^{4}(\%)$ & $\geq 10^{4}(\%)$ & Total $(\%)$ \\
\hline L. sg1 & $51(68.00)$ & $19(25.33)$ & $5(6.67)$ & $75(22.20)$ \\
\hline L. sgs $2-15$ & $99(54.10)$ & $45(24.59)$ & $39(21.31)$ & $183(49.39)$ \\
\hline L. non-pneumophila & $63(55.75)$ & $28(24.78)$ & $22(19.47)$ & $113(30.46)$ \\
\hline Total number of samples & $222(59.84)$ & $84(22.64)$ & $72(19.41)$ & $320(16.98)$ \\
\hline
\end{tabular}

Table 4 reports the water temperature and chlorine concentration of samples per Legionella spp. and serogroup.

Table 4. Water temperature and chlorine concentration of samples per Legionella spp. and serogroup.

\begin{tabular}{|c|c|c|c|c|c|c|}
\hline \multirow{2}{*}{\multicolumn{2}{|c|}{ Parameter }} & \multirow{2}{*}{$\begin{array}{l}\text { Number of } \\
\text { Samples }\end{array}$} & \multicolumn{4}{|c|}{$\begin{array}{c}\text { Positive Samples ( } \geq 50 \text { CFU/L) Legionella Species and } \\
\text { Serogroup (sg) }\end{array}$} \\
\hline & & & $\begin{array}{l}\text { Legionella } \\
\text { spp. * }\end{array}$ & $\operatorname{sg} 1$ & sg 2-15 & $\begin{array}{l}\text { L. non- } \\
\text { pneumophila }\end{array}$ \\
\hline \multirow{5}{*}{$\begin{array}{l}\text { Hot water } \\
\text { temperature } \\
\text { (Celsius) }\end{array}$} & $20-40$ & 197 & 62 & 19 & 45 & 16 \\
\hline & $41-50$ & 285 & 90 & 40 & 51 & 25 \\
\hline & $51-55$ & 170 & 38 & 11 & 26 & 10 \\
\hline & $>55$ & 304 & 17 & 5 & 13 & 3 \\
\hline & Total & 956 & 207 & 75 & 135 & 54 \\
\hline \multirow{5}{*}{$\begin{array}{l}\text { Cold water } \\
\text { temperature } \\
\text { (Celsius) }\end{array}$} & $10-20$ & 140 & 20 & 6 & 12 & 2 \\
\hline & $21-25$ & 497 & 64 & 16 & 36 & 21 \\
\hline & $26-30$ & 315 & 65 & 12 & 33 & 34 \\
\hline & $>30$ & 71 & 15 & 2 & 8 & 8 \\
\hline & Total & 1023 & 164 & 36 & 89 & 65 \\
\hline \multirow{4}{*}{$\begin{array}{l}\text { Residual } \\
\text { chlorine } \\
(\mathrm{mg} / \mathrm{L})\end{array}$} & $0-0.20$ & 424 & 110 & 29 & 48 & 50 \\
\hline & $0.21-0.50$ & 226 & 31 & 5 & 16 & 12 \\
\hline & $>0.51$ & 345 & 20 & 2 & 12 & 8 \\
\hline & Total & 995 & 161 & 36 & 76 & 70 \\
\hline
\end{tabular}

Note: ${ }^{*}$ total number of samples that tested positive to any L. pneumophila serogroup or any species.

\subsection{Univariate Examination of Factors}

Table 5 presents the risk factors for Legionella colonization per hotel characteristics, water sampling sites and physicochemical parameters. 
Table 5. Risk factors for Legionella colonization per hotel characteristics, water sampling sites and physicochemical parameters.

\begin{tabular}{|c|c|}
\hline Risk Factors & Odds Ratio ( $95 \%$ Confidence Interval) \\
\hline Boiler outflowing water temperature $<60^{\circ} \mathrm{C}$ & 27.5455 (1.6349-464.1095) \\
\hline Boiler returning hot water temperature $<55^{\circ} \mathrm{C}$ & $9.1698(1.1613-72.4041)$ \\
\hline No use of alternative disinfection procedures & $7.2528(2.2864-23.0074)$ \\
\hline Hot water temperature $<55^{\circ} \mathrm{C}$ & $5.9124(3.8358-9.4106)$ \\
\hline Boiler returning hot water temperature $<50{ }^{\circ} \mathrm{C}$ & 4.6667 (1.5273-14.2593) \\
\hline Incorrect application of WSP measures & $3.4593(2.0965-5.7078)$ \\
\hline Residual Chlorine $<0.2 \mathrm{mg} / \mathrm{L}$ & $3.3242(2.3876-4.6595)$ \\
\hline Start of season & $2.2562(1.3326-3.8200)$ \\
\hline Star classification $<4$ & $1.982(1.6442-2.3894)$ \\
\hline Exclusive use of solar panels and hot water temperature $<55^{\circ} \mathrm{C}$ & $1.9438(1.0398-3.6335)$ \\
\hline Absence of a Water Safety Plan & 1.7459 (1.4109-2.1604) \\
\hline $\begin{array}{l}\text { Population using municipality water distribution system } \\
<10.000 \text { residents }\end{array}$ & $1.4624(1.2243-1.7469)$ \\
\hline Cold water temperature $>25^{\circ} \mathrm{C}$ & $1.4238(1.0979-1.8464)$ \\
\hline Residual Chlorine $<0.2 \mathrm{mg} / \mathrm{L} \& \mathrm{pH}$ out of range & $1.4075(0.6882-2.8786)$ \\
\hline No guidance by the public health authority (1st inspection) & $1.249(1.0444-1.4965)$ \\
\hline End of season & $1.0643(0.7742-1.4630)$ \\
\hline High season period & $1.0578(0.8626-1.2971)$ \\
\hline Non-automated disinfection system & $0.9769(0.6039-1.5802)$ \\
\hline Exclusive use of solar panels & $0.9396(0.5886-1.5000)$ \\
\hline Seasonal operation & $0.8499(0.6968-1.0367)$ \\
\hline Hot water distribution system-distal room to boiler & $0.8217(0.6022-1.1212)$ \\
\hline Unsatisfactory operations according to the checklist & $0.6672(0.3539-1.2576)$ \\
\hline $\mathrm{pH}$ out of range & $0.5481(0.3432-0.8753)$ \\
\hline Number of rooms $>80$ & $0.4427(0.3652-0.5366)$ \\
\hline Number of beds $>200$ & $0.4351(0.3529-0.5366)$ \\
\hline Groundwater as a source of water supply & $0.3717(0.2564-0.5388)$ \\
\hline
\end{tabular}

\subsection{Inspection Results and Implementation of WSPs}

The results of 101 hotel inspections were analysed. Water storage tank protection, the cleaning of showers, residual chlorine concentration, and water temperatures were among the main findings. Table 5 presents the test results for risk factors for Legionella colonization per hotel characteristics, water sampling sites and physicochemical parameters. The inspection findings are summarized in Table S3.

\section{Discussion}

Our study demonstrated that approximately $63 \%$ of the hotels which were inspected following a Legionnaires' disease case notification were found to be colonized with Legionella spp. A retrospective cohort study of 357 touristic accommodation sites associated with two or more TALD cases conducted in 2011-2016, reported detection of Legionella spp. in $67.4 \%$ of the 340 accommodation sites for which results of environmental investigation were available [12]. The same study found that the detection of Legionella spp. in a water system was not shown to be associated with the risk of a further case [12]. A water system that has tested negative for Legionella does not exclude it from the possibility that this site was the source of infection. Moreover, a positive Legionella test does not prove that the water system is the source of infection. Increasing competencies of public health authorities for risk assessment and water sampling could contribute to the conducting of thorough and comprehensive follow-ups of cases, clusters and outbreaks associated with hotels.

During 2011-2016, Greece was among the countries with the highest proportions of accommodations associated with a TALD cluster (Italy $=42.6 \%$, Spain $=17.1 \%$, France $=14.6 \%$, Greece $=7.6 \%$ ) [12]. Unfortunately, it was not possible for the authors to associate epidemiological data for Legionnaires' disease with environmental investigation results.

Previous studies in Greek hotels that were not considered to be associated with Legionnaires' disease cases have demonstrated Legionella colonization in hotels in Thessaly and Corfu in 2018, where 38 (75\%) hotels were colonized by Legionella spp. [4]. Other studies revealed colonization rates of $86 \%$ in a 1989 study, $21 \%$ in 2007 in hotels across Greece, and $33 \%$ in hotels in southwest Greece [4,6]. This percentage is also comparable to 
three similar studies in Turkey, where colonization rates ranged between approximately $60 \%$ and $92 \%[13,14]$. Moreover, equivalent surveys in hotels in Italy showed colonization rates varying between $60 \%$ and $75 \%$ [15-17].

Apart from L. pneumophila (serogroups 1, 2, 3, 6, 7, 8, 13, 14, 15, and 2-15), other potentially pathogenic environmental species were also isolated, such as L. anisa, L. erythra, $L$. tusconensis, L. birminghamensis, L. londiniesis, L. oakridgensis and L. maceacherii [18]. Infection risks from non-pneumophila species should not be underestimated, especially in regard to L. anisa, which is the second most common species that has been reported worldwide, including on the island of Crete [7].

The most frequently isolated L. pneumophila serotypes were $1(30.96 \%)$ and $3(18.27 \%)$. ECDC's annual report indicates that "only $10 \%$ of cases were culture-confirmed $(10 \%)$ probably meaning that disease caused by Legionella species other than Legionella pneumophila is under-estimated" [2]. Significantly higher incidence rates were related to the hot water network $(36.81 \%)$ compared to the cold water network $(12.04 \%)$ and the sediment samples (21.43\%). Worldwide, cases of Legionnaires' disease are caused by L. pneumophila, and more than $80 \%$ of cases are caused by L. pneumophila serotype 1 [19].

A high proportion of cold water systems were found to be colonized (approximately $57 \%$ ). Cold water first catch samples, hot water samples after a two minute flush (rooms distal to boilers), water samples directly from boiler and hot water first catch samples (rooms closest to boilers) were significantly more frequently colonized with L. pneumophila serogroups 2-15 compared to L. pneumophila seroproup 1 and L. non-pneumophila. The colonization of distal rooms and boiler water could be attributed to the possible low temperature of the boiler water, as well as the length of piping and the reduction in water temperature as it reaches distal rooms. There were no significant differences in the sampling sites for L. pneumophila serogroup 1 compared with L. non-pneumophila. Our findings demonstrated that hotel water systems with poor temperature control, without alternative disinfection procedures, residual chlorine $<0.2 \mathrm{mg} / \mathrm{L}$, non-automated disinfection system seasonal operation, a star classification $<4$, a population using the municipality water distribution system $<10.000$ residents, and without guidance by public health authorities had higher odds of Legionella-positive results. A systematic literature review identified the following as contributing factors for potable water systems' colonization of hotels where cases of Legionnaires' disease had stayed: a lack of water recirculation features, blind ends or closed loops in the main building where patients/guests stayed, stagnation of hot water in the feedback circuit, poor temperature control and a lack of disinfectant residual [20]. The acceptable levels of chlorine concentration in hotel water systems are not effective in eradicating Legionella spp. in biofilms and/or when amoeba is present in the water system [21]. WSPs provide a multibarrier approach to ensure water safety, and do not rely only on routine chlorine disinfection to reduce Legionella risks $[8,19,22]$. Training hotel operators and system maintenance staff can increase awareness and competencies in implementing prevention and control measures.

Larger capacity hotels ( $>80$ rooms) had a lower risk of recording Legionella-positive tests. Our findings contradict the results of a retrospective cohort study of 357 touristic accommodation sites associated with two or more TALD cases conducted in 2011-2016. This study reported that the risk of a further Legionnaires' disease case was higher in accommodation sites with 36 to 67 rooms, + compared to those with less than 36 rooms, while accommodations with more than 67 rooms had the same risk as accommodations with 36 to 67 rooms. The same study found that "neither the detection of Legionella in the water system nor the type of disinfection were found to be associated with the risk of a further case" [12].

Hotel water systems that were linked with TALD and with the absence of a WSP had a higher risk of testing positive for Legionella spp. compared to hotels that were also linked with TALD but implemented a WSP. During the study period, water safety plan implementation was not mandatory for touristic accommodation facilities. However, it is expected with the recent legislation in Greece regarding water intended for human consumption, operators of hotels and other touristic accommodation sites will implement risk-based 
approaches [23]. The WSP methodology as described by WHO allows a site-specific process for the description of the water system, identification of different hazards and appropriate control measures $[8,19]$. It is expected to improve water systems' conditions and the provision of safer water to consumers.

\section{Conclusions}

The present study found that approximately $63 \%$ of the hotels which were inspected following a Legionnaires' disease case notification were found to be colonized with Legionella spp. The study also evaluated the significant factors that contribute to the maintenance, management and disinfection of water distribution systems, including the successful implementation of WSPs to improve hotel water supply and sanitation systems.

Chemical treatment and the monitoring of drinking water quality, including chlorine disinfection, $\mathrm{pH}$ adjustment, and water temperature control of hot water systems are recommended as control measures in water safety plans, in conjunction with other procedures. It has also been found that antiquated hotel buildings are at increased risk in terms of the safety and quality of the water in their distribution systems.

To conclude, risk assessment, environmental monitoring and disinfection of water systems, as well as the implementation of preventive control measures (WSPs) are the key elements for preventing contamination by pathogenic microorganisms in large public and private water distribution systems.

Supplementary Materials: The following are available online at https:/ /www.mdpi.com/article/10 .3390/w13162243/s1, Table S1: Summary laboratory examination results for Legionella spp. by culture per sample type, Table S2: Concentrations of Legionella non pneumophila spp. in samples collected from water systems (CFU/L), Table S3: Inspection results of hotel water distribution systems.

Author Contributions: A.P. (Antonios Papadakis) did the collection of the majority of the samples and the analysis of the results, and contributed to the writing of the article. M.K. did the analysis of the samples and the analysis of the results. D.C. did the analysis of the samples and contributed to the writing of the article. V.S. did the analysis of the samples and contributed to the writing of the article. V.A.M. contributed to the study design and writing of the manuscript. A.P. (Anna Psaroulaki) was in charge of the proper processing of the study and contributed to the writing of the article. All authors have read and agreed to the published version of the manuscript.

Funding: This research received no external funding.

Institutional Review Board Statement: Not applicable.

Informed Consent Statement: Not applicable.

Data Availability Statement: Not applicable.

Acknowledgments: We would like to thank all the environmental health inspectors of the Local Public Health Authorities of Crete Island who collected the environmental samples during all these years.

Conflicts of Interest: The authors have declared no conflict of interest.

\section{References}

1. European Legionnaires' Disease Surveillance Network (ELDSNet)—Operating Procedures. Available online: https://www.ecdc. europa.eu/en/publications-data/ european-legionnaires-disease-surveillance-network-eldsnet-operating-procedures (accessed on 13 August 2021).

2. Legionnaires' Disease-Annual Epidemiological Report for 2019. Available online: https://www.ecdc.europa.eu/en/ publications-data/legionnaires-disease-annual-epidemiological-report-2019 (accessed on 13 August 2021).

3. Chochlakis, D.; Sandalakis, V.; Panoulis, C.; Goniotakis, I.; Makridaki, E.; Tselentis, Y.; Psaroulaki, A. Typing of Le-gionella Strains Isolated from Environmental Samples in Crete, Greece, during the Period 2004-2011. J. Water Health 2013, 11, 762-771. [CrossRef] [PubMed]

4. Kyritsi, M.A.; Mouchtouri, V.A.; Katsioulis, A.; Kostara, E.; Nakoulas, V.; Hatzinikou, M.; Hadjichristodoulou, C. Le-gionella Colonization of Hotel Water Systems in Touristic Places of Greece: Association with System Characteristics and Physicochemical Parameters. Int. J. Environ. Res. Public Health 2018, 15, 2707. [CrossRef] [PubMed] 
5. Mavridou, A.; Lambiri, M.; Papadakis, J.A. A Fatality Resulting from a Case of Legionnaires' Disease on Hotel Premises. Water Res. 1994, 28, 2421-2423. [CrossRef]

6. Mouchtouri, V.; Velonakis, E.; Tsakalof, A.; Kapoula, C.; Goutziana, G.; Vatopoulos, A.; Kremastinou, J.; Hadjichris-todoulou, C. Risk Factors for Contamination of Hotel Water Distribution Systems by Legionella Species. Appl. Environ. Microbiol. 2007, 73, 1489-1492. [CrossRef] [PubMed]

7. Papadakis, A.; Chochlakis, D.; Sandalakis, V.; Keramarou, M.; Tselentis, Y.; Psaroulaki, A. Legionella Spp. Risk Assessment in Recreational and Garden Areas of Hotels. Int. J. Environ. Res. Public Health 2018, 15, 598. [CrossRef] [PubMed]

8. Guidelines for Drinking-Water Quality, 4th Edition, Incorporating the 1st Addendum. Available online: https://www.who.int/ publications-detail-redirect/9789241549950 (accessed on 13 August 2021).

9. European Technical Guidelines for the Prevention, Control and Investigation of Infections Caused by Legionella Species. Available online: https:/ / www.ecdc.europa.eu/en/publications-data/european-technical-guidelines-prevention-control-andinvestigation-infections (accessed on 13 August 2021).

10. ISO 5667-2:1991—Water Quality-Sampling. Available online: https://standards.iteh.ai/catalog/standards/iso/70148721-ae6f428b-93af-9ea314f2b75f/iso-5667-2-1991 (accessed on 13 August 2021).

11. ISO 19458:2006(En), Water Quality—Sampling for Microbiological Analysis. Available online: https://www.iso.org/obp/ui/\#iso: std:iso:19458:ed-1:v1:en (accessed on 13 August 2021).

12. Beauté, J.; Sandin, S.; de Jong, B.; Hallström, L.P.; Robesyn, E.; Giesecke, J.; Sparén, P.; on behalf of the European Legionnaires' Disease Surveillance Network. Factors Associated with Legionnaires' Disease Recurrence in Hotel and Holiday Rental Accommodation Sites. Eurosurveillance 2019, 24, 1800295. [CrossRef] [PubMed]

13. Erdogan, H.; Arslan, H. Colonization of Legionella Species in Hotel Water Systems in Turkey. J. Travel Med. 2007, 14, 369-373. [CrossRef] [PubMed]

14. Sepin Özen, N.; Tuğlu Ataman, Ş.; Emek, M. Exploring the Legionella Pneumophila Positivity Rate in Hotel Water Samples from Antalya, Turkey. Environ. Sci. Pollut. Res. Int. 2017, 24, 12238-12242. [CrossRef] [PubMed]

15. Bonetta, S.; Bonetta, S.; Ferretti, E.; Balocco, F.; Carraro, E. Evaluation of Legionella Pneumophila Contamination in Italian Hotel Water Systems by Quantitative Real-Time PCR and Culture Methods. J. Appl. Microbiol. 2010, 108, 1576-1583. [CrossRef] [PubMed]

16. Borella, P.; Montagna, M.T.; Stampi, S.; Stancanelli, G.; Romano-Spica, V.; Triassi, M.; Marchesi, I.; Bargellini, A.; Tatò, D.; Napoli, C.; et al. Legionella Contamination in Hot Water of Italian Hotels. Appl. Environ. Microbiol. 2005, 71, 5805-5813. [CrossRef] [PubMed]

17. Leoni, E.; Luca, G.D.; Legnani, P.P.; Sacchetti, R.; Stampi, S.; Zanetti, F. Legionella Waterline Colonization: Detection of Legionella Species in Domestic, Hotel and Hospital Hot Water Systems. J. Appl. Microbiol. 2005, 98, 373-379. [CrossRef] [PubMed]

18. Fang, G.D.; Yu, V.L.; Vickers, R.M. Infections Caused by the Pittsburgh Pneumonia Agent. Semin. Respir. Infect. 1987, 2, $262-266$. [PubMed]

19. World Health Organization. Legionella and the Prevention of Legionellosis; Bartram, J., Ed.; World Health Organization: Geneva, Switzerland, 2007; ISBN 978-92-4-156297-3.

20. Mouchtouri, V.A.; Rudge, J.W. Legionnaires' Disease in Hotels and Passenger Ships: A Systematic Review of Evidence, Sources, and Contributing Factors. J. Travel Med. 2015, 22, 325-337. [CrossRef] [PubMed]

21. Effect of Common Drinking Water Disinfectants, Chlorine and Heat, on Free Legionella and Amoebae-Associated Le-gionella. Available online: https:/ /journals.plos.org/plosone/article?id=10.1371/journal.pone.0134726 (accessed on 13 August 2021).

22. World Health Organization. Country Office for Bangladesh Guidelines for Implementation of Water Safety Plan for Hotel and Restaurant; World Health Organization, Country Office for Bangladesh: Dhaka, Bangladesh, 2016; ISBN 978-984-34-0833-4.

23. CMD (Common Ministerial Decision). Measures, Limits and Procedures for Reuse of Treated Wastewater; No. 145116; Ministry of Environment, Energy and Climate Change: Athens, Greece, 2011. (In Greek) 